\title{
XY SEGREGATION IN THE CRANE FLY TIPULA MAXIMA (DIPTERA: TIPULIDA)
}

\author{
BERNARD JOHN \\ Department of Zoology and Comporative Anatomy, \\ University College, Cardiff
}

Received 20.xi. 56

\section{INTRODUCTION}

IN some animals the $\mathrm{X}$ and $\mathrm{Y}$ chromosomes of the heterogametic sex do not pair at first prophase. Segregation then depends on some mechanism other than chiasma formation. Such heterogametic systems exist in several insect orders but only in the HemipteraHeteroptera has the mechanism of segregation been explained (Darlington, 1939). Here the $\mathrm{X}$ and $\mathrm{Y}$ chromosomes are unpaired at first metaphase but regularly congress and divide after the autosomes. The sex chromatids pair momentarily at the second division, co-orientate and then segregate. This behaviour depends upon a special spindle structure and a special centromere cycle.

The present paper is concerned with the analysis of a distinctive type of XY segregation in the male crane fly Tipula maxima.

\section{MATERIAL AND TECHNIQUE}

The testes of crane flies develop in the last (fourth) larval instar. The gonads of pupal and imaginal males consist of maturing spermatids and spermatozoa only. Tipula maxima is the largest of British crane flies. The larvæ frequent damp environments, burrowing just below the surface of saturated soil on the margins of woodland streams and pools. Fourth instars may be collected throughout the winter months, but the testes are not in an active state of division until March and April. By this time most of the larvæ are fully grown. The larvæ begin to pupate during April and adults are found from May to August.

The larvæ used in the present study were collected from Ogmore Vale, Glamorgan. $\mathrm{I}$ am indebted to T. Parsons of this department for the material and its identification. The larval testes are paired and lie attached to the inner side of the fat body at the junction of the mid and hind gut.

In order to remove the testes the posterior ends of larvæ were cut off under saline (Baker, I950, p. I82). This results in the fat body floating free. From here the gonads were removed with needles and transferred to $1: 3$ acetic-alcohol prior to squashing in acetic-orcein.

\section{OBSERVATIONS}

(i) Mitosis

The male mitotic complement includes six autosomes and a smaller pair of subequal sex chromosomes $(2 n=6 \mathrm{~A}+\mathrm{XY})$. All the chromosomes are metacentric and the mitotic partners show the marked somatic pairing characteristic of dipterans (plate I, fig. I). 
(ii) First meiotic division

Pre-meiotic resting nuclei contain a large chromocentre which represents the sex chromosomes. Charging of the autosomes begins at the centromere ( $c f$. Darlington, 1933). These centric blocks are

A.

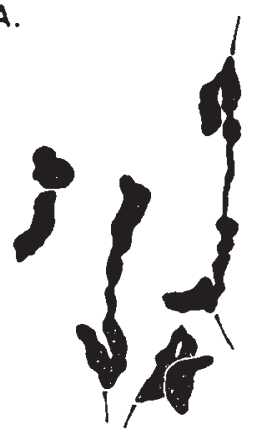

B.

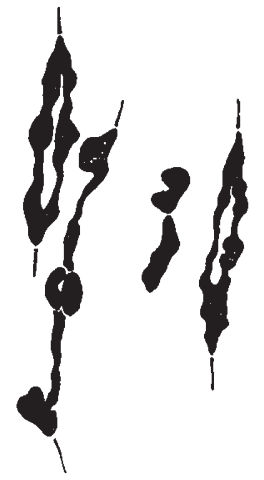

FIG. 1.-Early pre-stretch, subequal sex chromosomes still associated. In (A) two autosomes only are stretched. In (B) all three autosomes are affected. $\times 2000$.

sticky and at zygotene may associate with each other (plate I, fig. 2) or with the persistent scx chromocentre. These regions remain overcharged at pachytene (plate I, fig. 3).

A.

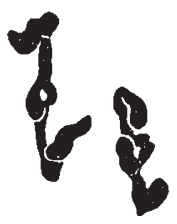

B.

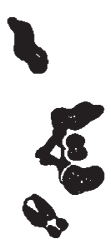

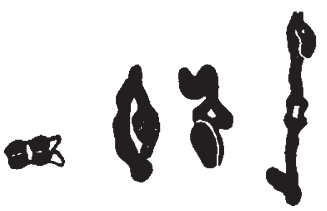

FIG. 2.-(A) Congression and (B) First metaphase. In (A) one sex univalent is still uncoiling; the other is divided and its centromeric region is undercharged ( $c f$. plate 2, fig. 3). In (B) both sex univalents have divided and in both the differential heterochromatic segments are undercharged. Note early neo-centromere activity in the undercharged end. $\times 2000$.

The autosomal bivalents generally have two interstitial chiasmata at diplotene and at this stage the sex association can be resolved into two sub-equal chromosomes which are not associated by chiasmata (plate I, fig. 5). Indeed they may exist as univalents which subsequently behave independently (plate I, fig. 4). Following diakinesis there is a pronounced and asynchronous pre-metaphase stretch ( $c f$. Hughes-Schrader, I943; John and Lewis, 1957). This results in the disruption of persistent sex associations, the $\mathrm{X}$ and $\mathrm{Y}$ then moving to opposite poles (plate I, fig. 8). A pre-metaphase movement has also been observed in living spermatocytes of Tipula lateralis (Dietz, I 956$)$.

The sex chromosomes uncoil during pre-stretch and show that they are double (plate II, figs. 3 and 4 ; fig. 2). They also develop 
a regional charge differentiation and can then be seen to consist of four distinct segments :-

(i) A terminal segment, normally charged (like the autosomes).

(ii) An interstitial segment, undercharged, which contains the centromere.

(iii) An interstitial segment normally charged.

(iv) A terminal segment, undercharged.

Terminalisation in the autosomes is incomplete and on recontraction they congress (plate II, fig. 5). The sex univalents generally congress after the autosomes have begun their asynchronous anaphase movement (plate II, figs. 6 and 7). The sex chromosomes divide equationally at first anaphase and are both completely undercharged at this stage. In the separation of the sister sex chromatids one of the ends leads the way to the pole (plate II, figs. 8-II). This frequently results in an arrangement where the sex chromatids form a linear sequence bridging the distance between the telophase groups. During the lag between autosomal anaphase and the division of the sex univalents the spindle increases in length and may become slightly curved.

\section{(iii) Second meiotic division}

The $\mathrm{X}$ and $\mathrm{Y}$ chromosomes having divided at the first division do not divide at the second. During second prophase the heterozygous sex chromatids pair. This appears to be controlled by the simultaneous recharging, in the $\mathrm{X}$ and $\mathrm{Y}$, of the two segments which decharged precociously at first pro-metaphase. Pairing usually begins at the terminal segments and is consolidated by the association of the two interstitial centric segments (plate III, figs. 2-4). On only two occasions have I found the terminal charged segment of one chromatid in association with the interstitial segment of its partner and viceversa (plate III, fig. 6). Undercharged regions are not closely associated : they lie parallel and slightly apart.

In this condition the centromeres of the sex pair co-orientate and the association congresses to the edge of the spindle (plate III, fig. 5). Segregation of the $\mathrm{X}$ and $\mathrm{Y}$ seems to depend on two forces :-

(i) Active repulsion between the centric segments (plate III, figs. 7 and 8).

(ii) Active mobility in the undercharged ends (plate III, figs. 5 and 9-12).

\section{DISCUSSION}

In all other XY tipulid species so far studied the sex chromosomes agree with those of $\mathcal{T}$. maxima in that they do not pair at prophase of meiosis (Bauer, r931 ; Wolf, r94 I ; Dietz, r956, and Bauer, r956, quoted in Dietz). In these forms, however, the $\mathrm{X}$ and $\mathrm{Y}$ chromosomes 
segregate at first anaphase and then divide equationally at second meiosis. White (I949) compared this type of segregation with the distance pairing of neuropteran sex chromosomes (Naville and de Beaumont, 1933, 1936) and on this basis suggested that the tipulids evolved from neuropteroid ancestors. There is nothing to support this suggestion; the sex univalents move onto the equator at first anaphase and only after this do they move undivided to opposite poles. How this regular segregation is controlled has never been discussed.

At the onset of meiosis in $T$. maxima both sex chromosomes are positively charged and are associated non-specifically. This is probably due to the characteristic stickiness of heterochromatin (Darlington, I947; Pätau, I948; Vaarama, I954). The lapse of this association during first prophase similarly can be correlated with a progressive reduction in charge. This, together with the pre-stretch, results in the $\mathrm{X}$ and $\mathrm{Y}$ chromosomes separating as two univalents.

In Cimex (Darlington, I 939) and Luzula (Thomas, I950) centromere precocity has been shown to follow overcharging at first prophase. The same correlation is found in $T$. maxima. At pre-stretch the univalents move towards one pole; presumably therefore their centromeres must auto-orientate at attachment to the spindle. But the univalents invariably return to the equator ( $c f$. Dietz, i 956). Probably, therefore, the univalent centromeres re-orientate during prestretch. In heterotypi cchromosomes the metaphase centromere, although undercharged, cannot be identified. This could be due to the centromere being screened by the meiotic spiral (Östergren, I95I). In T. maxima the sex univalents uncoil during pre-stretch. This could lead to the disappearance of the centric screen so that the centromere then becomes functionally bilateral, accounting for the return of the univalents from the poles to the equator.

The centromeres are not the only kinetic centres active during meiosis. Secondary centres occur in one of the end segments of both the $\mathrm{X}$ and $\mathrm{Y}$. The kinetic potentiality of these active ends results in their poleward flexion so that at both meiotic divisions these ends lead the way to the poles. This behaviour of the terminal and secondary centres identifies them as neo-centromeres (Vilkomerson, I950; Walters, 1952). The nucleic acid cycle of the sex chromosomes of $\mathcal{T}$. maxima is anomalous. Secondary centric activity in this species may therefore be explained in terms of Darlington's (1950) diffusion theory.

Two series of observations support the suggestion that the activity of the sex neo-centromeres is adaptive :-

(i) Undercharged segments lead to a failure of separation (Darlington and La Cour, I940; Koller, I946). The sex neo-centromeres develop only in the undercharged terminal segments. 


\section{Plate I}

Fig. 1.-Mitotic pro-metaphase $(2 n=8)$; strong somatic pairing. Subequal sex chromosomes at seven o'clock. $\times 2000$.

Fig. 2.-Zygotene. Three autosomal centric blocks fused in a heterochromatic sticky association. Persistent sex chromocentre at seven o'clock. $\times 1400$.

Frg. 3.-Pachytene. Autosomes with precharged proximal blocks. Sex chromocentre at six o'clock. $\times$ I 400 .

Frg. 4.-Diplotene. Autosomes chiasmate. Sex association disrupted. $\times$ I 400 .

Fig. 5.-Diplotene. Sex association analysable into two subequal chromosomes but persistent. $\times 1400$.

Fig. 6.-Diakinesis. Sex association clearly non-chiasmate. $\times 1400$.

Fig. 7.-Early pre-stretch. Sex association disrupting. Note asynchrony of autosomal movement. $\times 1400$

Fig. 8.-Mid pre-stretch. Autosomal stretching markedly asynchronous. Sex univalents widely separate. $\times 1400$. 

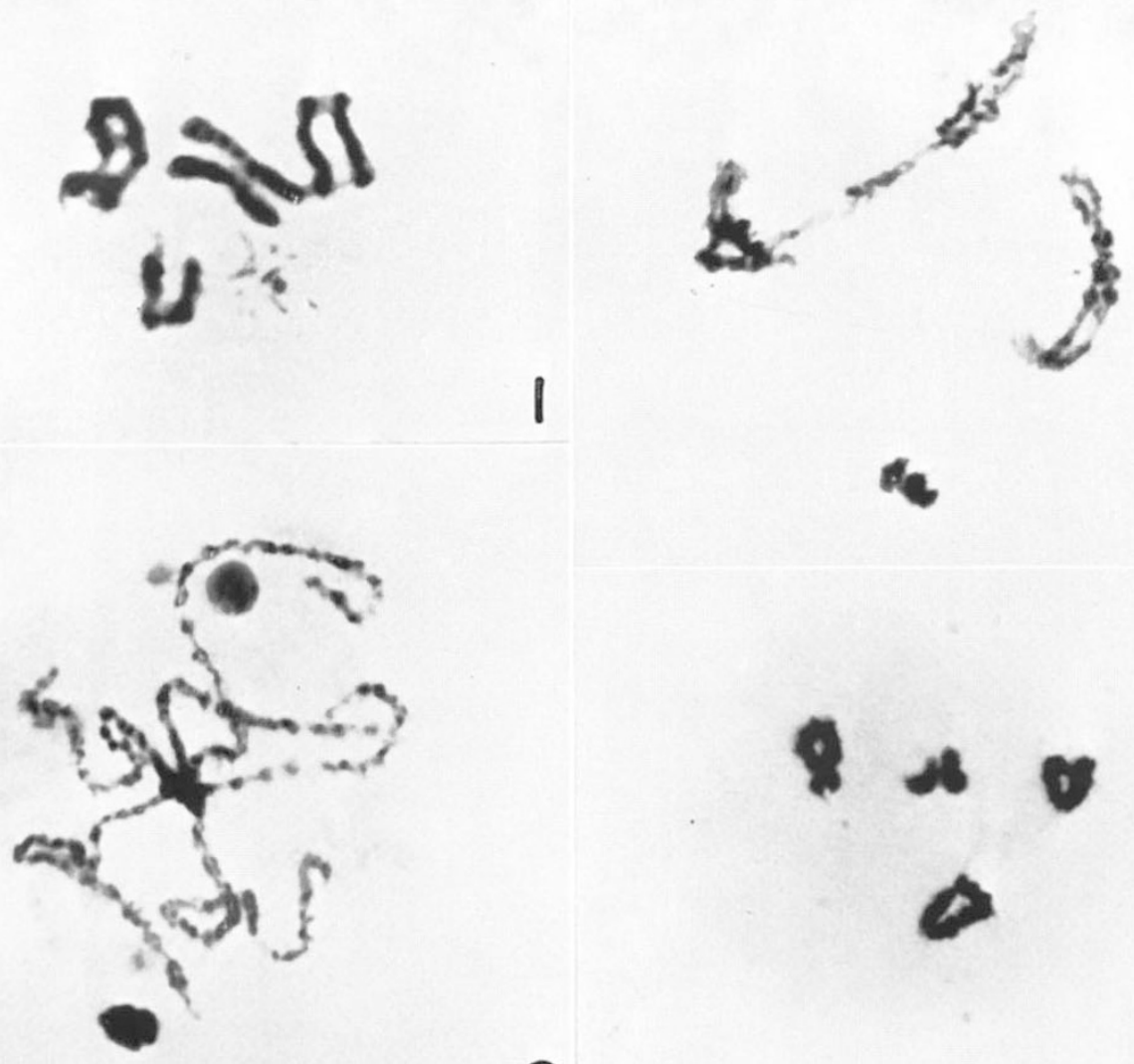

I

4

5

$8+0$

$\Delta$

2

6
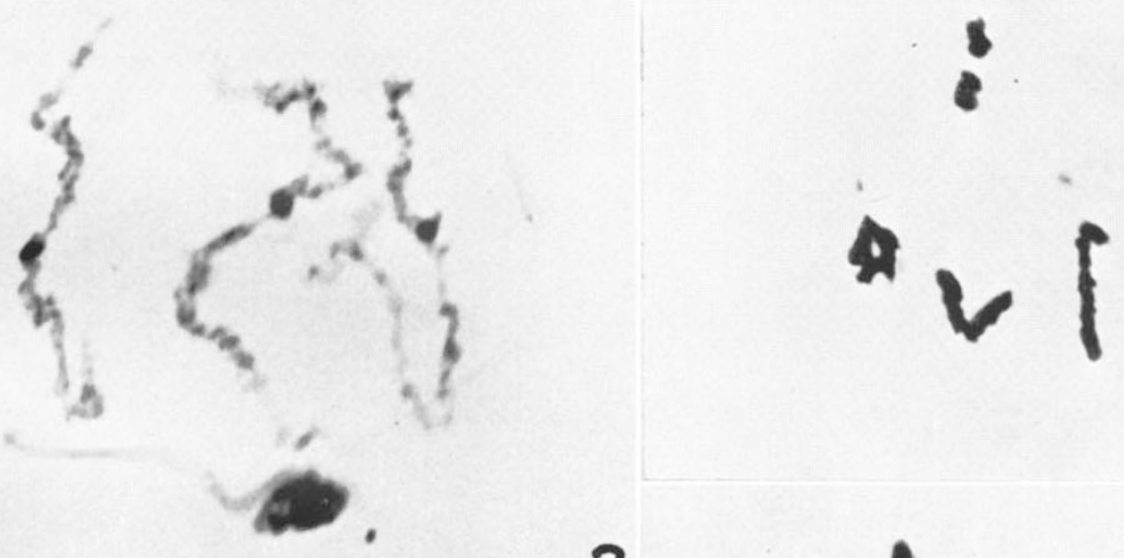

3

-
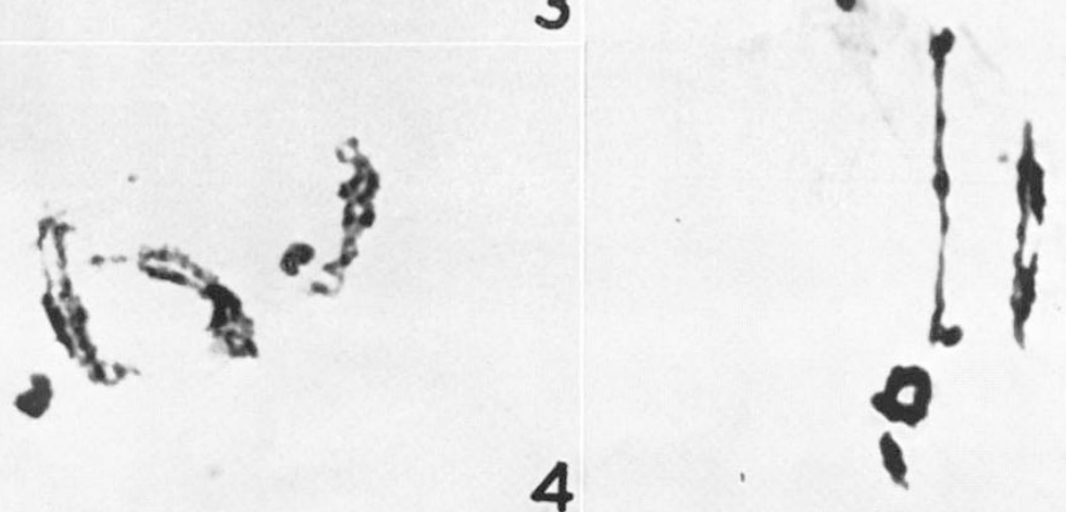

8 


\section{Plate II}

Fig. I.-Early recontraction. Note asynchrony of behaviour. $\times 1400$.

Fig. 2.-Mid recontraction. Sex univalents still maximally separated and uncoiling. $\times$ I 400 .

Fig. 3.-Late recontraction. $\times$ I 4 oo. Compare with fig. 2A.

Fig. 4.-Early congression. Note differential charging of the divided univalents. $\times$ I 400 .

Fig. 5.-Metaphase I. Sex univalents lying on the edge of the spindle. Terminalisation incomplete. $\times$ I 400 .

Fig. 6.-Early anaphase I. Note asynchrony of separation. $\times$ I 400 .

Fig. 7.--Mid anaphase I. Divided univalents aligned on spindle equator. $\times 1400$.

Figs. 8, 9 and 10.-Progressive stages in the separation of daughter sex chromatids at anaphase $I$ as the result of neo-centric activity in the undercharged chromatid ends. $\times 4000$.

Fig. i I.-Late anaphase I. Sex chromatids separated, undercharged and lagging. Note increased spindle length. $\times$ I 400 . 

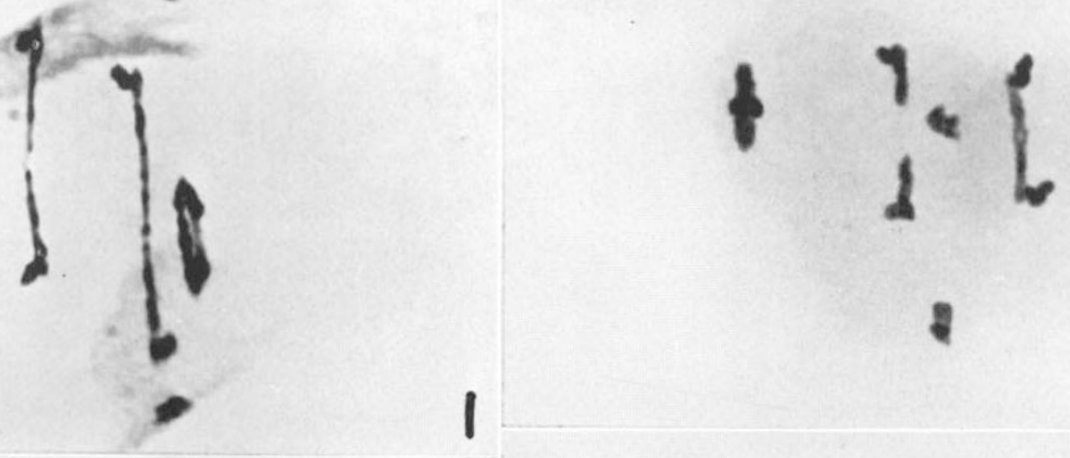

6

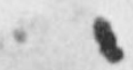

$1 ! 1$

-

483

3

2

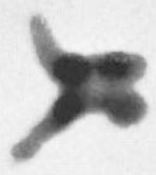

8

9

10

8 .

4

H $\ldots$

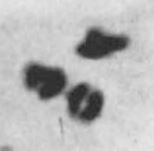

4

1.

5 
(ii) The centromeres of univalents are characteristically weak (Darlington, 1939, 1947). The sex neo-centromeres seem to be strong since at both divisions they may become active before the autosomal centromeres (plate III, fig. 5).

Neo-centric activity also occurs in one autosome which is not heterochromatic. This activity is variable; it is most pronounced at the second division (plate III, fig. 5).

CHROMASY

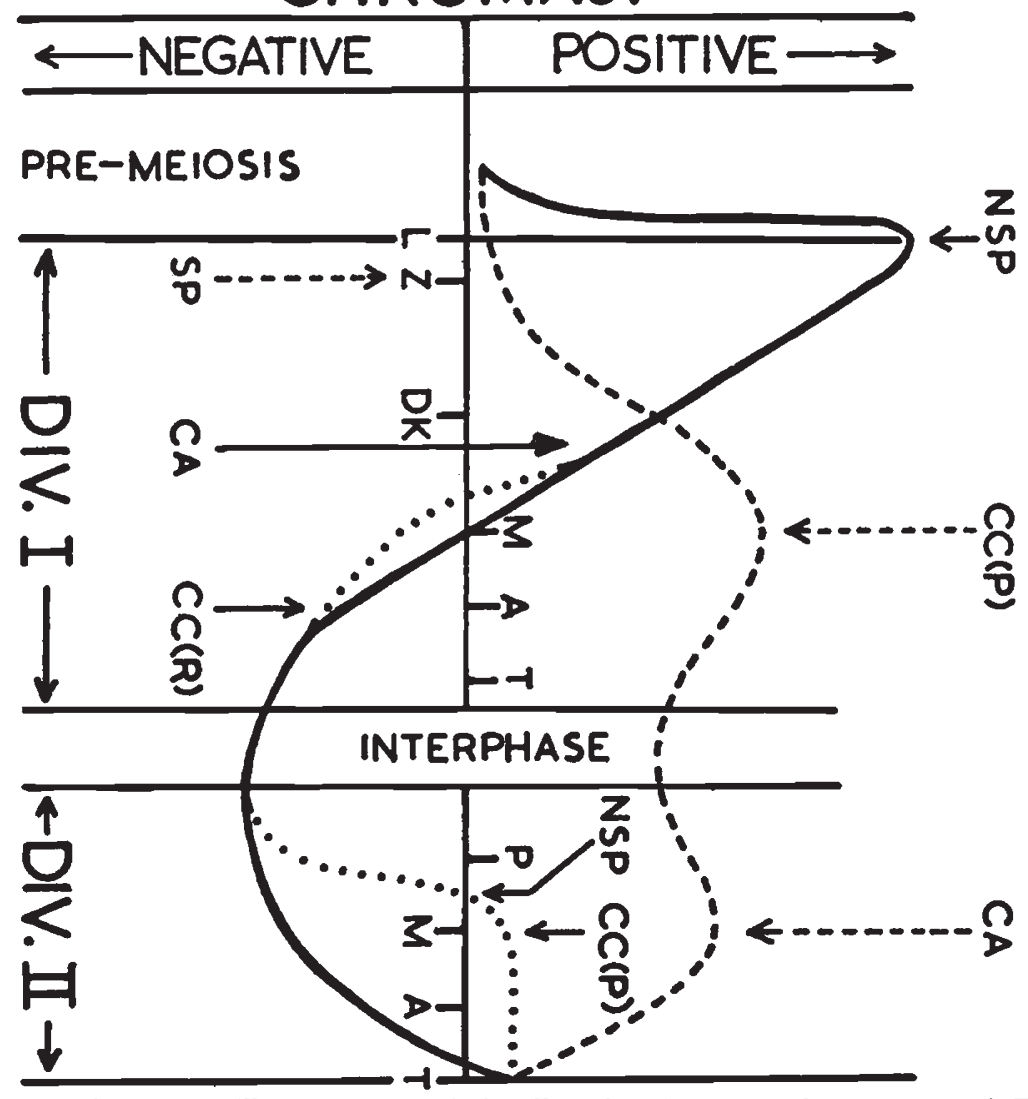

Fig. 3.-Diagram to illustrate the meiotic allocycly of the sex chromosomes of Tipula maxima and its relation to autosomal charging. The broken line and broken arrow arms refer to the euchromatic autosomes (-.-). The solid line and solid arrow arms refer to the heterochromatic sex chromosomes (-). The dotted line refers to the two heterochromatic segments with precocious allocycly (...).

$\mathrm{SP}=$ Specific pairing : NSP $=$ Non-specific pairing.

$\mathrm{CC}(\mathrm{P})=$ Centromeres co-orientated (products of pairing).

$\mathbf{C C}(\mathbf{R})=$ Centromeres co-orientated (products of reproduction).

$\mathrm{CA}=$ Centromeres auto-orientated.

Both sex chromosomes consist of two kinds of heterochromatin differing from each other, as well as from euchromatin, in their charge cycle. These two kinds alternate with one another so that the $\mathrm{X}$ and $\mathrm{Y}$ each consist of four segments. One end and a centric segment have the same cycle; the segment between these two and the other end having a different cycle (fig. 3). At the second division the two 
former segments recharge precociously and this seems to regulate the association of the heterozygous sex chromatids. This in turn determines the co-orientation of the sex centromeres on the second division spindle.

These two segments with a precocious charging may represent adaptively modified pairing segments. The only other cases where two distinct heterochromatic cycles have been described within one chromosome are those which relate to the pairing and differential segments of certain mammalian sex chromosomes (Koller, r938 ; I946; Pontecorvo, I943, I944; Sharman and Barber, 1952). In a limited sense, therefore, one can still speak of " pairing " segments in T. maxima although these segments enjoy no gene exchange.

\section{SUMMARY}

I. In $T$. maxima the $X$ and $Y$ chromosomes do not pair at zygotene but are associated non-specifically at the onset of meiosis by the stickiness of heterochromatin.

2. Relaxation of the $\mathrm{XY}$ association during first prophase is correlated with a progressive reduction in charge. This, together with the pre-metaphase stretch, results in their separating into two univalents.

3. The sex univalents divide at first anaphase. At second metaphase the $\mathrm{X}$ and $\mathrm{Y}$ pair with one another and their centromeres co-orientate. This association is regulated by the precocious and localised recharging of two segments.

4. The equational first division of the sex chromosomes has entailed the development of a special mechanism of segregation at second anaphase. This is related both to the reversed centromere cycles of the $\mathrm{X}$ and $\mathrm{Y}$ and the development of neo-centric activity in the undercharged terminal segments.

I wish to thank Professor C. D. Darlington for criticism and advice in the preparation of this paper.

\section{REFERENCES}

BAKER, J. R. 1950. Cytological Technique. London: Methuen.

BAUER, H. 1931. Die Chromosomen von Tipula paludosa Meig. in Eibildung und Spermatogenese. Zeit. Zell. Mik. Anat., 14, 138-193.

Darlington, C. D. 1933. Meiosis in Agapanthus and Kniphofia. Cytologia, 4, 229-240. DARLInGton, C. D. I939. The genetical and mechanical properties of the sex chromosomes. V. Cimex and the Heteroptera. 7. Genet., 3.9, I0I-1 37 .

Darlington, c. D. 1947. Nucleic acid and the chromosomes. S.E.B. Symposia, 1, 252-269. Cambridge : Univ. Press.

Darlington, c. D. I950. Mendel and the Determinants. Chap. I5, pp. 315-332. Genetics in the 2oth Century. New York : Macmillan.

DARLington, C. D., AND LA COUR, L. F. I 940 . Nucleic acid starvation of chromosomes in Trillium. 7. Genet., 4o, 185-213.

DIETZ, R. I956. Die Spermatocytenteilungen der Tipuliden. II. Graphische Analyse der Chromosomenbewegung während der Prometaphase I im Leben. Chromosoma, 8, 183-211. 


\section{Plate III}

Fig. 1.-Early prophase II. Heterozygous and subequal sex chromatids unpaired, undercharged and despiralising. $\times 4000$.

FIGs. 2, 3 and 4--Progressive stages in the pairing of the heterozygous sex chromatids during second prophase. $\times 4000$.

FIG. 5.-Metaphase II. Note marked neo-centric activity in the terminal segment of one of the autosomal chromatids and in the undercharged end segments of both sex chromatids. $\times 1400$.

Fig. 6.-Alternative pairing of sex chromatids by the reverse association of pairing blocks. $\times 4000$.

Figs. 7,8,9 and 10.-Progressive stages in the separation of the heterozygous sex chromatids at second meta-anaphase. $\times 4000$.

Fig. II.-Anaphase II. Slight lagging of sex chromatids. $\times 1400$.

FIG. 12-Telophase II. Note terminal neo-centric activity in the sex chromatids and in one of the autosomes. $\times 1400$. 


\section{en.}

ave $4+2$ and

1
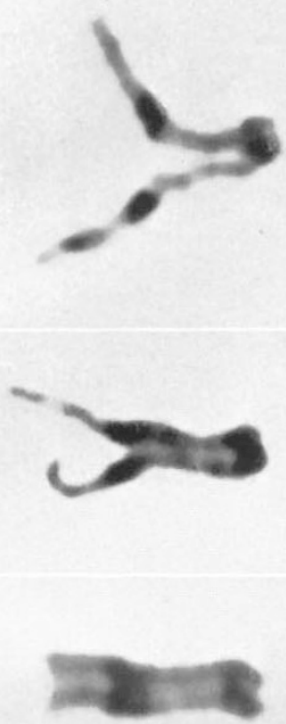

와 오

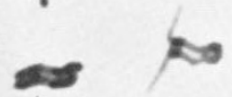

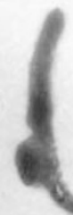

10

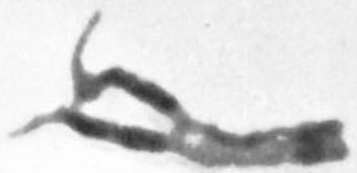

5

4

2

3

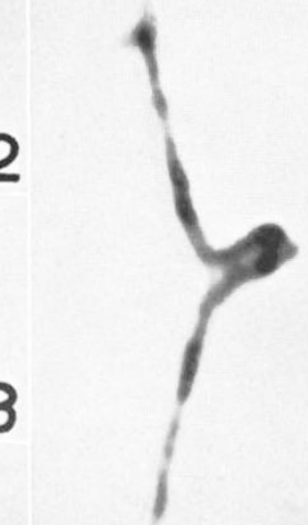

9
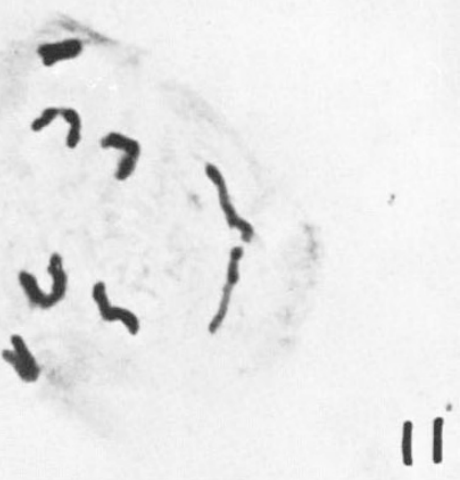

$\left.n^{\prime}\right)^{\prime}$

6

8

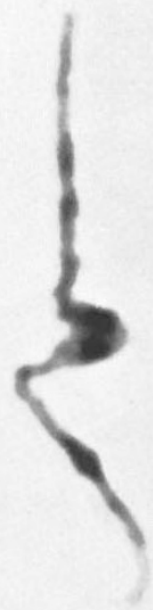

II

$v^{n}$

7 
HUGHES-SChrader, s. 1943. Polarisation, kinetochore movement and bivalent structure in the meiosis of male mantids. Biol. Bull., 85, 265-30o.

JOHN, B., AND LEWIS, K. R. 1957. Studies on Periplaneta americana. I. Experimental analysis of male meiosis. Heredity, $I I, \mathrm{I}-9$.

KOLLER, P. C. 1938. The genetical and mechanical properties of the sex chromosomes. IV. The golden hamster. 7. Genet., 36, i $77-195$.

KOLLER, P. C. 1946. Control of nucleic acid charge on the X-chromosome of the hamster. P.R.S., B, 133, 313-326.

NAVILle, A., AND DE BEAUMONT, J. 1933. Recherches sur les chromosomes des Nevroptères. Arch. Anat. Micr., 29, 199-243.

NAVille, A., AND DE BEAUmont, J. 1936. Recherches sur les chromosomes des Nevroptères. Deuzieme partie. Arch. Anat. Micr., 32, 27 I-302.

östergren, G. 1951. The mechanism of co-orientation in bivalents and multivalents. The theory of orientation by pulling. Hereditas, 37, 85-156.

PÄTAU, K. I948. X-segregation and heterochromasy in the spider, Aranea reamuri. Heredity, 2, 77-100.

PONTECORvo, G. 1943. Meiosis in the striped hamster (Cricetulus griseus Milne Edw.) and the problem of heterochromatin in mammalian sex chromosomes. P.R.S. Edin., B. 62, 32-42.

PONTECORvo, G. I 944. Structure of heterochromatin. Nature, 153, 365-367.

SHARMAN, G. B., AND BARBER, H. N. 1952. Multiple sex chromosomes in the marsupial Potorus. Heredity, 6, 345-355.

THомas, P. т. 1950. Centromere precocity in Luzula. Heredity, 4, 137-138.

VAARAma, A. 1954. Cytological observations on Pleurozium schreberi with special reference to centromere evolution. Ann. Bot. Soc. "Vanamo", 28, I-57.

vilkomerson, H. i95o. The unusual meiotic behaviour of Elymus wiegandii. Exp. Cell. Res., I, 534-542.

WALTERS, M. S. 1952. Atypical chromosome movement in meiotic anaphase of Bromus pitensis $\times$ B. marginatus. Amer. F. Bot., 39, 619-625.

White, M. J. D. I949. Cytological evidence on the phylogeny and classification of the Diptera. Evolution, 3, 252-261.

WOLF, E. 1941. Die chromosomen in der Spermatogenese einiger Nematoceren. Chromosoma, 2, 192-246. 